\title{
The relationship between mitral annular systolic velocity and ejection fraction in patients with preserved global systolic function of the left ventricle
}

Ivaylo Rilkov Daskalov*, Ivona Kirilova Daskalova², Lilia Davidkova Demirevska ${ }^{1}$ and Borislav Georgiev Atzev³

\begin{abstract}
Background: The aim of the study was to investigate the relationship between the ejection fraction (EF) and the mitral annular systolic velocity (Sm) in patients with preserved left ventricular systolic function (EF>55\%). The study task was to evaluate whether the assessment of Sm(avg) can be used as an alternative to the Simpson's method in assessment of the EF. The expected benefit was that Sm could be used to predict EF, when EF is difficult to assess due to poor image quality (IQ).
\end{abstract}

Method: Sm was obtained by spectral pulse wave Tissue Doppler Imaging (pwTDI) from the lateral and septal sites of the mitral annulus (MA) and an averaged value was calculated - Sm(avg). EF was assessed using Simpson's rule. Participants were divided into controls $(n=70)$, hypertensive (HTN, $n=56)$, HTN with diastolic dysfunction (HTN/DD, $n=65)$, HTN with diabetes mellitus (HTN/DM, n=52) and HTN with DD and DM (HTN/DD/DM, n=65).

Results: $\mathrm{Sm}(\mathrm{avg})$ showed strong correlation with $\mathrm{EF}(r=0.978 ; \mathrm{p}<0.0001)$. There were no significant differences between the correlation coefficients between the subgroups and the controls. The mathematical model that the study recommended to assess the $\mathrm{EF}$ is: $E F=45.0+2 \times \operatorname{Sm}$ (avg).

Conclusion: The assessment of Sm(avg) could be used as an alternative to EF. This approach may be useful especially when the IQ is poor. The method maintains high accuracy and reproducibility in prediction of the EF.

Keywords: Mitral annulus velocity, Ejection fraction, EF, Systolic function, Sm, TDI

\section{Background}

Left ventricular (LV) longitudinal shortening during ejection reflects mitral annulus (MA) descent and has been used as an index of the global systolic function [1-5]. Previous studies using routine $M$ mode, twodimensional echocardiography and colour-coded $M$ mode TDI measures of MA systolic excursions have shown close correlation with EF which is an accepted standard reference of LV systolic function [6-8]. The measurement of MA systolic velocities (Sm) is advantageous compared to the other quantitative echocardiographic techniques, because it is not dependent on the

\footnotetext{
* Correspondence: ivodaskalov@mail.bg

'Department of Cardiology and Intensive Care, Cardiology Clinic, Military

Medical Academy, 3 Georgi Sofiiski Blvd, Sofia 1606, Bulgaria

Full list of author information is available at the end of the article
}

endocardial definition [9]. This parameter, measured by pwTDI, correlates more strongly with plasma BNP levels than those measured by M-mode. It provides a simple, sensitive, accurate and reproducible tool for early diagnosis of LV dysfunction [10].

Even though $\mathrm{Sm}$ of the MA correlates closely with the EF, they are not directly connected [10]. The relationship is probably nonlinear in patients with reduced EF in contrast to the subjects with preserved EF where the relationship is linear. Many factors influence the EF/Sm(avg) ratio, such as gender, age, presence and grade of hypertension (HTN), diastolic dysfunction (DD), coronary heart disease (CHD), diabetes mellitus $(\mathrm{DM})$ etc $[11,12]$. 


\section{Objective}

The aim of this study was to investigate whether the assessment of $\mathrm{Sm}(\mathrm{avg})$ can be used as an alternative to the Simpson's method in assessment of the EF. The study task was to find an equation from which EF could be predicted. The benefit of this approach is that $\mathrm{Sm}$ is not dependent on IQ and therefore could apply to subjects with poor IQ.

\section{Method}

The study protocol was approved by the local Ethics Committee of the Military Medical Academy Sofia Bulgaria. All participants agreed and signed the informed consent form of the study. Subjects were randomly selected between January 2009 and August 2011 from outpatient clinic and hospitalized patients at the Department of Cardiology and Intensive Care.

Assessment of participants was performed by experienced cardiologists using a standard protocol, including questions on medical history, family history, cardiovascular risk factors, alcohol intake, physical activity and drug history. A physical examination which included blood pressure, anthropometric measurements, and an electrocardiogram was performed. Standard laboratory blood tests were performed to identify subjects with DM (fasting blood glucose, HbA1C), dyslipidemia (cholesterol, LDL, HDL, TG), anemia (Hb), significant liver (AST, ALT, GGT, bilirubin) and kidney disease (creatinine, urea). Subsequently, eligible subjects were invited to undergo echocardiography. Echocardiography was performed in a left lateral decubitus position, with a digital commercial harmonic imaging ultrasound system, ALOKA PROSOUND SSD5500 SV, equipped with a $2.5 \mathrm{MHz}$ phasedarray transducer. The images were acquired during a breath hold. Left ventricular dimensions were obtained in the parasternal short axis view, and LV mass was calculated using the Devereaux formula and indexed to height to give the LV mass index (LVMI). Left ventricular hypertrophy was investigated by LVMI and the thickness of the walls. The EF was assessed using the biplane Simpson's method [13]. Left atrial volume was calculated from 3 measurements of left atrial dimensions using the formula for an ellipse and indexed to body surface area to obtain the left atrial volume index (LAVI). Diastolic function of the LV was assessed using the following indices: ratio E/A, Valsalva maneuver $\Delta \mathrm{E} / \mathrm{A}$, ratio $\mathrm{E} / \mathrm{e}$, LAVI, pulmonary artery systolic pressure (PAS), IVRT/T E-e' and Ar-A [14].

Myocardial velocities were measured on-line using spectral pwTDI $[15,16]$. The sample volume was guided by color-coded images, which were acquired using low velocity, high-intensity myocardial signals at a high frame rate $(>150 \mathrm{MHz})$. The imaging angle was adjusted to ensure as near to a parallel alignment of the beam as possible with the myocardial segment of interest. Longitudinal contraction of the LV was investigated by average peak systolic velocity of the mitral annulus - Sm(avg) using two positions, septal and lateral, from the apical 4-chamber view (Figure 1, Figure 2).

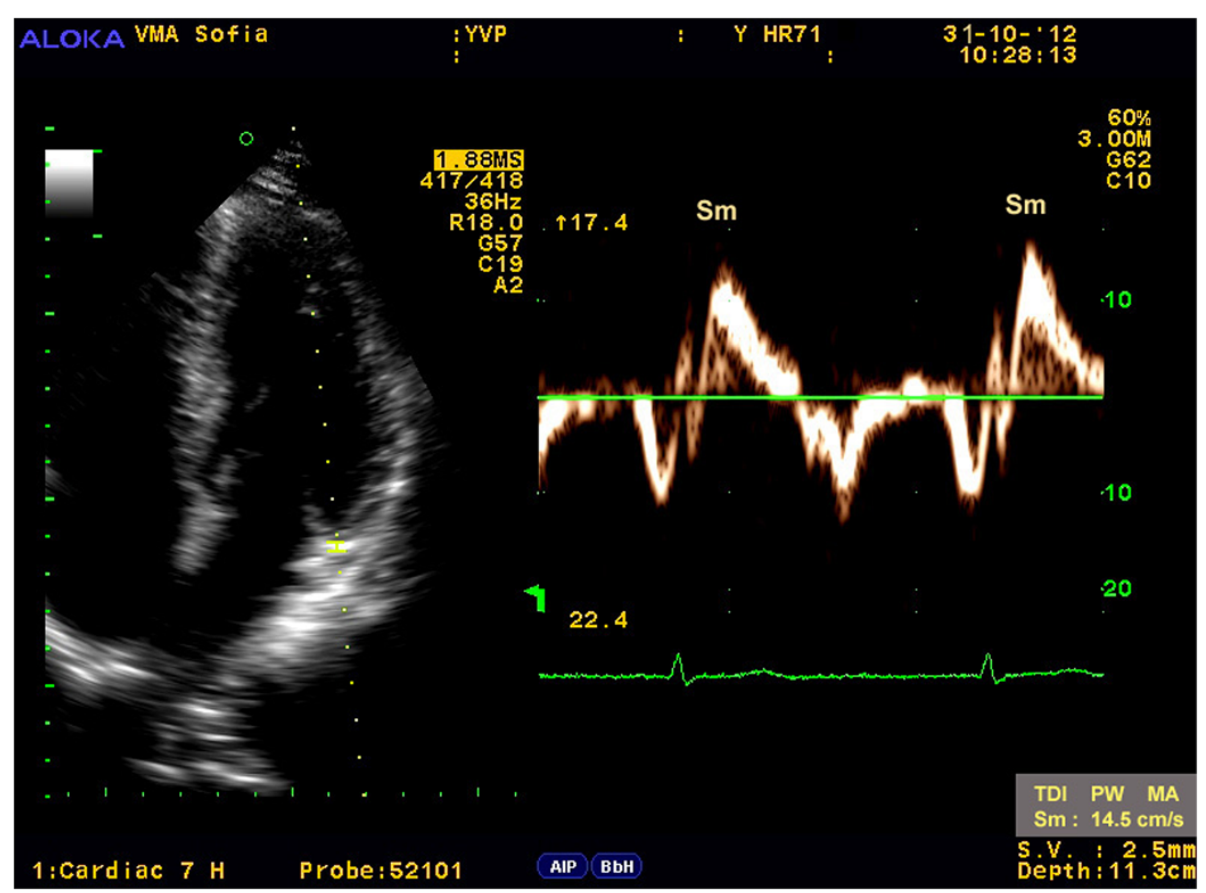

Figure 1 The picture presents how to obtain Sm from the lateral site of the MA using spectral pwTDI. 


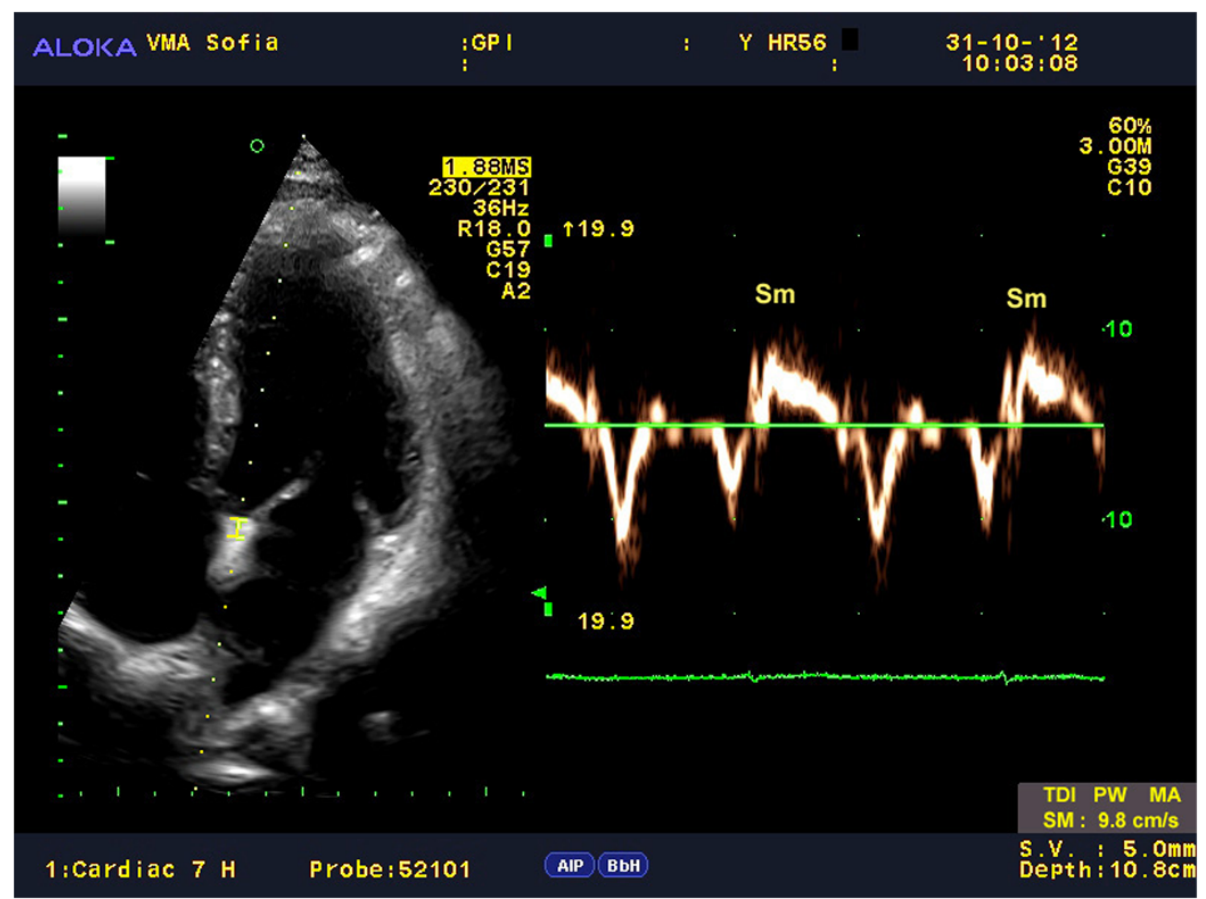

Figure 2 The picture presents how to obtain Sm from the septal site of the MA using spectral pwTDI.

In accordance with the study protocol, 3 consecutive cardiac cycles were analyzed, and the mean value was calculated. After each evaluation, the results were processed with the ALOKA D4D software and digitally stored (post-processing) to evaluate the reliability of the results. Two experienced echocardiographers evaluated the results of 10 randomly selected participants from every group, independently from one another, for the analysis of intra- and inter-observer variability.

Table 1 Demographics and clinical characteristics of the study population

\begin{tabular}{|c|c|c|c|c|c|c|}
\hline Participants $(n=308)$ & Controls $(n=70)$ & HTN pts. $(n=56)$ & HTN/DD pts. $(n=65)$ & HTN/DM pts. $(n=52)$ & HTN/DD/DM pts. $(n=65)$ & $\overline{p \text {-value }}$ \\
\hline Gender/male (n, \%) & $40(57.1 \%)$ & $30(53.5 \%)$ & $30(46.2 \%)$ & $28(53.8 \%)$ & $32(49.2 \%)$ & 0.899 \\
\hline Mid age (years) & $45 \pm 10$ & $53 \pm 10$ & $56 \pm 10$ & $55 \pm 10$ & $60 \pm 10$ & 0.462 \\
\hline Height (cm) & $170 \pm 14$ & $168 \pm 16$ & $168 \pm 14$ & $169 \pm 13$ & $165 \pm 14$ & 0.241 \\
\hline Weight (kg) & $66 \pm 7$ & $67 \pm 9$ & $65 \pm 9$ & $69 \pm 9$ & $68 \pm 9$ & 0.311 \\
\hline $\mathrm{BMI}\left(\mathrm{kg} / \mathrm{m}^{2}\right)$ & $22.9 \pm 2$ & $23.3 \pm 2$ & $23.1 \pm 2$ & $24.5 \pm 2$ & $24.1 \pm 2$ & 0.233 \\
\hline Heart rate (bpm) & $70 \pm 10$ & $72 \pm 10$ & $68 \pm 10$ & $64 \pm 10$ & $65 \pm 10$ & 0.08 \\
\hline Systolic BP (mmHg) & $125 \pm 5$ & $128 \pm 5$ & $130 \pm 5$ & $118 \pm 5$ & $120 \pm 5$ & $<0.0001$ \\
\hline Diastolic BP (mmHg) & $70 \pm 8$ & $78 \pm 8$ & $80 \pm 8$ & $77 \pm 4$ & $76 \pm 3$ & $<0.0001$ \\
\hline EF (Simpson's method \%) & $64.4 \pm 2 \%$ & $63.7 \pm 4 \%$ & $63.9 \pm 4 \%$ & $64.9 \pm 4 \%$ & $62.9 \pm 4 \%$ & 0.161 \\
\hline Fasting blood glucose & $4.8 \pm 1.0$ & $5.0 \pm 1.0$ & $5.0 \pm 0.7$ & $6.0 \pm 1.5$ & $7 \pm 1.5$ & $<0.0001$ \\
\hline $\mathrm{HbA1c}$ & $4.0 \pm 1.0$ & $4.5 \pm 1.0$ & $4.7 \pm 1.0$ & $5.0 \pm 1.0$ & $5.3 \pm 1.0$ & $<0.0001$ \\
\hline DM type II & 0 & 0 & 0 & $29(55.5 \%)$ & $30(46.2 \%)$ & $<0.0001$ \\
\hline HTN mild & 0 & $22(39.3 \%)$ & $23(35.3 \%)$ & $20(39.4 \%)$ & $25(38.5 \%)$ & $<0.0001$ \\
\hline HTN moderate & 0 & $18(32.1 \%)$ & $25(38.5 \%)$ & $23(44.2 \%)$ & $27(41.5 \%)$ & $<0.0001$ \\
\hline HTN severe & 0 & $16(28.6 \%)$ & $17(26.2 \%)$ & $9(17.3 \%)$ & $13(20 \%)$ & $<0.0001$ \\
\hline DD impared relaxation & 0 & 0 & $35(53.8 \%)$ & 0 & $34(52.3 \%)$ & $<0.0001$ \\
\hline DD peudonarmalisation & 0 & 0 & $20(30.7 \%)$ & 0 & $20(30.7 \%)$ & $<0.0001$ \\
\hline DD restriction & 0 & 0 & $10(15.4 \%)$ & 0 & $11(16.9 \%)$ & $<0.0001$ \\
\hline
\end{tabular}




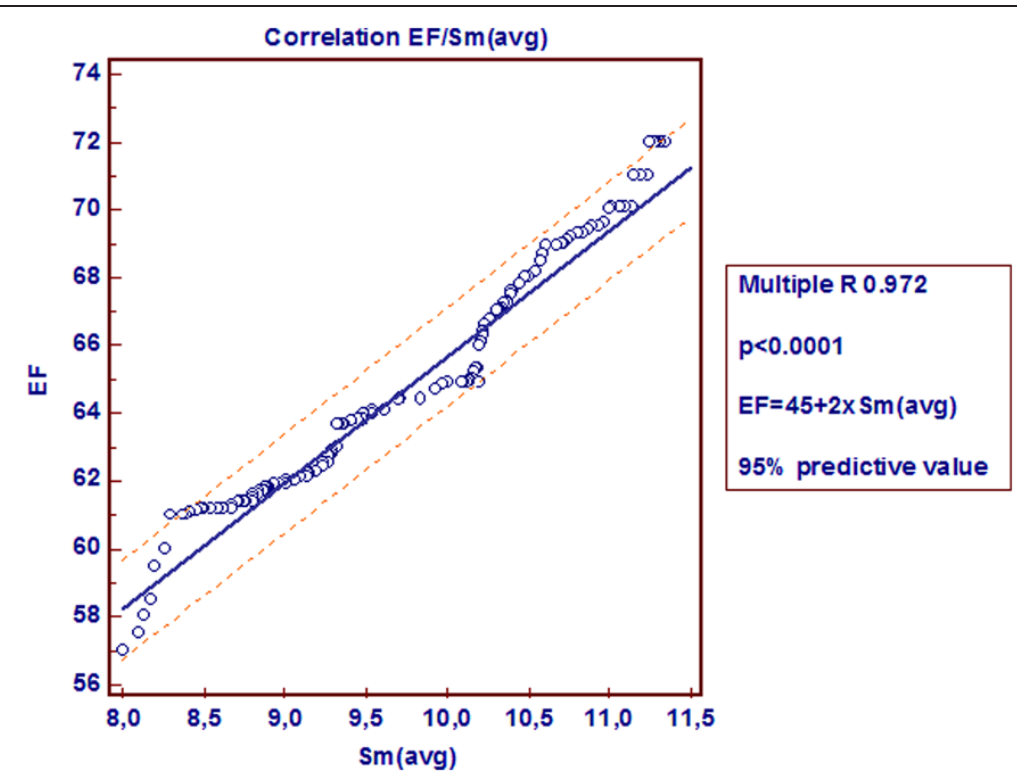

Figure 3 The scatter diagram presents a regression line, as a result of the linear correlation between EF and Sm(avg).

\section{Statistical analysis}

The statistical analysis was performed using SPSS (Statistical Package for Social Science) version 15.0 for Windows. The significance level for this study was set at $p<0.05$. Categorical data were shown by frequencies and percentages. ANOVA was used to analyze the demographics and clinical characteristics of the study population. We performed the analysis in subgroups using an unpaired t-test. To determine the strength of the correlation between the variables, we used the Pearson's $\mathbf{r}$ correlation coefficient. Continuous variables and their association with age, gender, HTN, DD and DM were

Table 2 Multiple regression analysis, correlation coefficients, significance, $95 \%$ confidence interval standard deviation and mathematical model

\begin{tabular}{|c|c|c|c|}
\hline $\begin{array}{l}\text { Number of } \\
\text { patients }(n=308)\end{array}$ & $\begin{array}{l}\text { Correlation } \\
\text { coefficient (R) }\end{array}$ & $\begin{array}{l}\text { 95\% confidence } \\
\text { interval (Cl) }\end{array}$ & $\begin{array}{l}\text { Asymptotic } \\
\text { significance (p) }\end{array}$ \\
\hline $\begin{array}{l}\text { Multiple correlation } \\
\text { EF/Sm(avg) }\end{array}$ & 0.978 & $0.975-0.980$ & $<0.0001$ \\
\hline Controls $(n=70)$ & 0.936 & $0.932-0.938$ & $<0.0001$ \\
\hline HTN $(n=56)$ & 0.882 & $0.880-0.886$ & $<0.0001$ \\
\hline $\mathrm{DD}(\mathrm{n}=65)$ & 0.906 & $0.902-0.910$ & $<0.0001$ \\
\hline $\mathrm{DM}(\mathrm{n}=52)$ & 0.948 & $0.942-0.950$ & $<0.0001$ \\
\hline \multirow{2}{*}{$\begin{array}{l}\text { HTN/DD/DM } \\
(n=65)\end{array}$} & 0.963 & $0.960-0.968$ & $<0.0001$ \\
\hline & Meaning & $\begin{array}{l}\text { Standard } \\
\text { Deviation (SD) }\end{array}$ & \\
\hline Constant & 45.0 & \pm 1.882 & $p<0.0001$ \\
\hline Coefficient & 2.0 & \pm 0.191 & $p<0.0001$ \\
\hline Equation & \multicolumn{3}{|c|}{$E F=45.0+2 \times S m(a v g)$} \\
\hline
\end{tabular}

assessed using multiple regression analysis. Reference ranges are presented as values denoting the 95\% confidence interval for correlations. The mathematical model was created by linear regression analysis. Inter- and intraobserver variability of Sm(avg) and EF were assessed using intraclass correlation coefficients (ICC).

\section{Results}

Participants were patients with hypertension (HTN, $\mathrm{n}=56$ ), HTN and diastolic dysfunction (HTN/DD, $\mathrm{n}=65$ ), HTN and diabetes mellitus (HTN/DM, n=52) and patients with HTN, DD and DM (HTN/DD/DM, n=65). All these patients were compared with a control group consisting of age-matched healthy subjects (controls, $\mathrm{n}=70$ ). All the patients were in sinus rhythm and had a preserved EF (>55\%). There were no patients with signs and symptoms of coronary heart disease (CHD), or more than a mild valvular heart disease (Table 1 ).

The aim of the study was to establish a quantitative method for evaluation of EF using Sm(avg). This approach presents an opportunity to predict EF by using an equation. In this equation the main independent variable is Sm (avg), which is obtained by spectral pwTDI.

Table 3 The influence of gender on the EF/Sm(avg) correlation and Sm(avg) velocity

\begin{tabular}{|c|c|c|c|}
\hline \multirow[t]{2}{*}{ Gender $(n=308)$} & \multirow{2}{*}{$\begin{array}{l}\text { Men }(n=160) \\
\text { Pearson's } \\
\text { correlation }\end{array}$} & \multicolumn{2}{|c|}{ Women $(n=148)$} \\
\hline & & $\begin{array}{l}\text { Pearson's } \\
\text { correlation }\end{array}$ & Significance \\
\hline $\mathrm{EF} / \mathrm{Sm}(\mathrm{avg})$ & $r=0.906(p=0.002)$ & $r=0.881(p=0.004)$ & $p=0.279$ \\
\hline Sm(avg) & $10.3 \pm 0.9(\mathrm{~cm} / \mathrm{s})$ & $9.2 \pm 0.12(\mathrm{~cm} / \mathrm{s})$ & $p<0.0001$ \\
\hline $\mathrm{EF}(\%$, mean, $\pm \mathrm{SD})$ & $66 \pm 2$ & $63 \pm 3$ & $p<0.0001$ \\
\hline
\end{tabular}


Table 4 The influence of age on the EF/Sm(avg) correlation and Sm(avg) velocity

\begin{tabular}{|c|c|c|c|c|}
\hline \multirow[t]{2}{*}{ Age/years $(n=308)$} & $20-40(n=75)$ & $41-60(n=123)$ & $61-80(n=110)$ & \multirow[t]{2}{*}{ Significance } \\
\hline & Pearson's correlation & Pearson's correlation & Pearson's correlation & \\
\hline EF/Sm(avg) & $r=0.978(p=0.002)$ & $r=0.934(p=0.044)$ & $r=0.889(p=0.02)$ & $P=0.625$ \\
\hline Sm(avg) & $11.2 \pm 0.1(\mathrm{~cm} / \mathrm{s})$ & $9.6 \pm 0.1(\mathrm{~cm} / \mathrm{s})$ & $8.6 \pm 0.1(\mathrm{~cm} / \mathrm{s})$ & $P<0.0001$ \\
\hline$E F(\%$, mean $\pm S D)$ & $67 \pm 2$ & $64 \pm 2$ & $62 \pm 2$ & $P<0.0001$ \\
\hline
\end{tabular}

The quantification of EF by equation has an advantage that $\mathrm{Sm}$ is minimally dependent on IQ, as well as a disadvantage that the mathematical model requires memorization of the two constants.

This study demonstrated a linear correlation between EF and Sm(avg) for investigated subjects with preserved global systolic function (Figure 3).

The multiple regression analysis demonstrated strong correlation between investigated variables. There was no significant difference between the subgroups regarding the strength of the correlation. Therefore it was possible to recommend a general mathematical model for the entire study population (Table 2).

Many factors influence the relationship of EF/Sm(avg) and could change the defined equation. These are: gender, age, HTN, DD, DM, CHD, anemia, chronicle renal diseases etc. In this study only the influences of gender and age, HTN, DD and DM were investigated. The data demonstrated that gender and age influence $\mathrm{Sm}(\mathrm{avg})$ in a way that higher velocities are observed in men while they decrease linearly with age. However, changes of the $\mathrm{EF} / \mathrm{Sm}(\mathrm{avg})$ correlation were not significant; therefore there was no need to correct the defined mathematical model (Tables 3 and 4).

The data demonstrated that HTN, DD and DM influence $\operatorname{Sm}(\mathrm{avg})$. In patients with HTN without DD there was a tendency to weaken the $\mathrm{EF} / \mathrm{Sm}$ (avg) correlation. In subgroup with HTN/DD, we observed a reverse tendency. In patients with HTN/DM correlation was stronger. These tendencies did not differ significantly between subgroups. Therefore, it was not necessary to correct the general equation. Regarding Sm(avg), there was a tendency to decrease the velocity in each group, depending on the grade of HTN, DD and/or DM. Combination of these conditions increased the severity of $\mathrm{Sm}$ (avg) deceleration.

According to our data, we can state that there was a significant decrease of $\mathrm{Sm}(\mathrm{avg})$ velocity $(\mathrm{p}<0.04)$, which differentiates controls from other subgroups. Subjects with HTN define a cut-offs $(<10.2 \mathrm{~cm} / \mathrm{s})$ as a result of Sm deceleration, which depends on the grade of HTN and co-morbidity. This deceleration could be mild (HTN), moderate (HTN/DD, HTN/DM) or severe (HTN/DD/DM) (Table 5).

To assess the reliability of the measurements, we used intraclass correlation coefficients (ICC). Two experienced echocardiographers evaluated the results of 10 randomly selected subjects from every subgroup, independently from one another, for the analysis of intra- and interobserver variability.

Analyzing the results, we could state that $\mathrm{Sm}(\mathrm{avg})$ and EF demonstrated better than good reliability for one as well as for two independent investigators. It is important to note that there were small fluctuations in the strength of agreement between subgroups and within groups. These changes reflected realistic variability of the measurements, depending on co-morbidity, gender and age, and, mostly, on the quality of echo images. In healthy subjects, both methods were equivalent in assessing the global systolic performance. In all others subgroups there was a prevalence of TDI obtained Sm(avg). This was strong evidence for the benefits of the spectral pwTDI whenever the assessment of EF (by Simpson's rule) is problematic due to poor IQ (Table 6).

\section{Discussion}

This study evaluated the prediction of EF by Sm only in patients with preserved EF. Spectral pwTDI could be used as an alternative examination when EF is difficult to assess or the results are controversial. The study demonstrated a simple approach to predicting EF using $\mathrm{Sm}$ (avg) from spectral pwTDI.

This approach (quantification) is based on a linear equation where estimated $\mathrm{Sm}(\mathrm{avg})$ could be used to calculate EF. This is a simple, cheaper and faster method compared to cardiac MRI, CT or contrast echocardiography. The quantitative approach presents an opportunity to predict EF using an equation. This equation

Table 5 The influence of HTN, DD and DM on EF/Sm(avg) correlation and Sm(avg)

\begin{tabular}{|c|c|c|c|c|c|c|}
\hline Participants $(n=308)$ & Controls $(n=70)$ & HTN $(n=56)$ & $H T N / D D(n=65)$ & $H T N / D M(n=52)$ & $H T N / D M / D D(n=65)$ & $\overline{p \text {-value }}$ \\
\hline Pearson's $(r)$ & $0.936(p=0.030)$ & $0.882(p=0.002)$ & $0.906(p=0.045)$ & $0.948(p=0.004)$ & $0.963(p=0.022)$ & 0.543 \\
\hline $\operatorname{Sm}(\operatorname{avg})(\mathrm{cm} / \mathrm{s})$ & $10.4-10.2$ & $10.2-9.9$ & $9.8-8.8$ & $10.2-8.8$ & $8.8-8.3$ & 0.04 \\
\hline$E F(\%$, mean $\pm S D)$ & $66 \pm 2$ & $65 \pm 2$ & $64-62$ & $65-62$ & $62-61$ & $<0.0001$ \\
\hline
\end{tabular}


Table 6 Assessment of the reliability of the measurements of EF and Sm(avg) by ICC

\begin{tabular}{|c|c|c|c|c|c|c|}
\hline Participants $(n=308)$ & ICC (1 observer) & $95 \% \mathrm{Cl}$ & Strength of agreement & ICC (2 observers) & $95 \% \mathrm{Cl}$ & Strength of agreement \\
\hline Controls $(n=10)$ & \multicolumn{2}{|c|}{ Single measures } & \multicolumn{4}{|c|}{ Average measures } \\
\hline EF (\%) & 0.9337 & $0.9020 \div 0.9553$ & Very good & 0.9653 & $0.9485 \div 0.9772$ & Very good \\
\hline $\mathrm{Sm}$ (avg) $(\mathrm{cm} / \mathrm{s})$ & 0.8634 & $0.8010 \div 0.9010$ & Very good & 0.9216 & $0.8901 \div 0.9450$ & Very good \\
\hline \multicolumn{7}{|l|}{ HTN $(n=10)$} \\
\hline EF (\%) & 0.6337 & $0.6020 \div 0.7553$ & Good & 0.7653 & $0.6485 \div 0.7772$ & Good \\
\hline$S m_{(a v g)}(\mathrm{cm} / \mathrm{s})$ & 0.8337 & $0.8015 \div 0.8080$ & Very Good & 0.9059 & $0.8095 \div 0.9210$ & Very Good \\
\hline \multicolumn{7}{|l|}{ HTN/DD $(n=10)$} \\
\hline EF (\%) & 0.6841 & $0.6224 \div 0.7509$ & Good & 0.7790 & $0.6183 \div 0.7894$ & Good \\
\hline $\mathrm{Sm}$ (avg) $(\mathrm{cm} / \mathrm{s})$ & 0.7838 & $0.7131 \div 0.8121$ & Very Good & 0.8254 & $0.8111 \div 0.9211$ & Very Good \\
\hline \multicolumn{7}{|l|}{ HTN/DM $(n=10)$} \\
\hline EF (\%) & 0.6549 & $0.6338 \div 0.7009$ & Good & 0.6919 & $0.6759 \div 0.7479$ & Good \\
\hline $\mathrm{Sm}$ (avg) $(\mathrm{cm} / \mathrm{s})$ & 0.7625 & $0.7346 \div 0.8434$ & Very Good & 0.7784 & $0.8115 \div 0.9300$ & Very good \\
\hline \multicolumn{7}{|l|}{ HTN/DD/DM $(n=10)$} \\
\hline EF (\%) & 0.6841 & $0.6324 \div 0.7509$ & Good & 0.6790 & $0.6183 \div 0.7194$ & Good \\
\hline $\mathrm{Sm} \mathrm{avg}_{(\mathrm{cm} / \mathrm{s})}$ & 0.7945 & $0.7234 \div 0.8222$ & Very Good & 0.8854 & $0.8005 \div 0.9401$ & Very good \\
\hline
\end{tabular}

The ICC is a measure of the reliability of measurements or ratings. The table reports two coefficients with their respective $95 \% \mathrm{Cl}$. Single measures: this is an index for the reliability of the ratings for one, typical, single rater and average measures which is an index for the reliability of different raters averaged together. (<0.20 Poor; 0.21-0.40 Fair; 0.41-0.60 Moderate; 0.61-0.80 Good; 0.81-1.00 Very good).

uses Sm(avg), as well as a constant and a coefficient. The method is clinically useful due to the minimal dependency of Sm on the IQ. In contrast, EF demonstrates strong dependency on the visibility of the endocardial contour when using Simpson's method.

Regrettably, clinical practice shows that the use of mathematical models has a few evident disadvantages. First of all, equations are not very well accepted due to the need of memorizing many constants. These constants always generate standard error of estimation, which cannot be avoided and should be kept in mind. Furthermore, these equations are rarely included in the software of the echo machines.

For quantitative analysis of the EF, it could be applied to the general mathematical model: $E F=45.0+2{ }_{X} S m$ (avg).

The study confirmed dependency of the longitudinal systolic contraction on gender and age. Most researchers supported the hypothesis that Sm decreases with age and in women [17-20]. Our study supported this conclusion.

Several studies have demonstrated that patients with HTN, CHD, DD and DM have lower systolic and early diastolic velocities in the MA compared to the controls [21-26]. Similar conclusions, especially for the systolic velocities, were presented in this study except CHD patients.

Finally, we have reached the general conclusion that regardless of the above-mentioned tendencies in patients with HTN, DD and DM, no correction in the explanatory equation is necessary. The reason is that no statistically significant differences between groups in $\mathrm{EF} / \mathrm{Sm}$ (avg) correlation coefficients were observed.

One important limitations of this study was that the results were not valid for $\mathrm{CHD}$ patients and could not be used for them without further investigation. Another limitation was the lack of subgroups with atrial fibrillation, conduction abnormalities, pacemakers and prosthetic valves $[27,28]$. Therefore, we could not make any inferences about these specific conditions.

Another important limitation is that the correlation between EF and Sm in low ejection fraction was not examined. Therefore all results could be applied only to patients with preserved EF.

\section{Conclusion}

The prediction of EF by $\mathrm{Sm}(\mathrm{avg})$ is a simple method, not time consuming, with high accuracy and reproducibility. The relationship between EF/Sm(avg) can be assessed by equation.

Finally, the mathematical model is valid only for a demonstrated subgroup of patients with preserved EF.

Competing interests

The authors declare that they have no competing interests.

\section{Authors' contributions}

IRD and IKD planned the study. IRD and LDD investigated all patients, performed measurements and analyzed the data. IRD performed statistical analysis and wrote the manuscript. BGA, LDD and IKD made a critical review of the paper. All authors read and approve the final version of the manuscript. 


\section{Acknowledgement}

The authors would like to thank Mrs. Gabriela Alexandrova Yordanova and Mr. Dimitar Alexandrov Simidchiev for their assistance in writing and editing this manuscript, data management, statistical analysis and patient collaborations.

\section{Author details}

${ }^{1}$ Department of Cardiology and Intensive Care, Cardiology Clinic, Military Medical Academy, 3 Georgi Sofiiski Blvd, Sofia 1606, Bulgaria. ²Department of Endocrinology and Metabolic Disorders, Endocrinology, Military Medical Academy, 3 Georgi Sofiiski Blvd, Sofia 1606, Bulgaria. ${ }^{3}$ Department of Cardiology, University Hospital "St.Ekaterina", 52A Pencho Slaveikov Blvd, Sofia 1000, Bulgaria.

Received: 22 March 2013 Accepted: 16 October 2013 Published: 26 October 2013

\section{References}

1. Gulati VK, Katz WE, Follansbee W, et al: Mitral annular descent velocities by Tissue Doppler as an index of global left ventricular function. Am J Cardiol 1996, 77:979

2. Simonson JS, Schiller NB: Descent of the base of the left ventricle: an echocardiographic index of left ventricular function. J Am Sot Echocardiogr 1989, 2:25-35.

3. Pai RG, Bodenheimer MM, Pai SM, et al: Usefulness of systolic excursion of the mitral annulus as an index of left ventricular systolic function. Am J Cardiol 1997, 67:222-224

4. Jones $\mathrm{CJH}$ : Functional importance of the long-axis dynamics of the human left ventricle. Br Heart J 1990, 63:215-220.

5. Feigenbaum H, Zaky A, Nasser WK: Use of ultrasound to measure left ventricular stroke volume. Circularion 1967, 38:1092-2099.

6. Emilsson K, Alam M, Wandt B, et al: The relation beteen mitral annulus motion and ejection fraction. J Am Soc Echocardiograph 2000, 13:896-901.

7. Vinereanu D, Khokhar A, Tweddel AC, Fraser AG: Estimation of global left ventricular function from the velocity of long-axis shortening. Echocardiography 2002, 19:177-185.

8. Fukuda K, Oki T, Tabata T, et al: Regional left ventricular wall motion abnormalities in myocardial infarction and mitral annular descent velocities studied with pulsed tissue Doppler imaging. J Am Soc Echocardiograph 1998, 11:841-848.

9. Yuda S, Inaba Y, Fujii S, Kokubu N, Yoshioka T, Sakurai S, Nishizato K, et al: Assessment of left ventricular ejection fraction using long-axis systolic function is independent of image quality: a study of tissue Doppler imaging and m-mode echocardiography. Echocardiography 2006, 23(10):846-852.

10. Elnoamany MF, Abdelhameed AK: Mitral annular motion as a surrogate for left ventricular function: correlation with brain natriuretic peptide levels. Eur J Echocardiogr 2006, 7(3):187-198. Epub 2005 Jul 19.

11. Emilsson $\mathrm{K}$, Wandt $\mathrm{B}$ : The relation beteen mitral annulus motion and ejection fraction changes with age and the heart size. Clin Physio/ 2000, 20:44-49.

12. Mogelvang R, Sogaard P, Pedersen SA, et al: Tissue Doppler echocardiography in person with hypertension, diabetes, or ischemic heart disease: the Copenhagen City Heart Study. Eur Heart J 2009, 30:731-739

13. Lang RM, Bierig M, Devereux RB, Flachskampf FA, Foster E, Pellikka PA, Picard MH, Roman MJ, Seward J, Shanewise JS, Solomon SD, Spencer KT, Sutton MS, Stewart WJ: Recommendations for chamber quantification: a report from the American society of echocardiography's guidelines and standards committee and the chamber quantification writing group. J Am Soc Echocardiogr 2005, 18:1440-1463.

14. Nagueh S, Appleton C, Gillebert T, et al: Recommendations for the Evaluation of Left Ventricular Diastolic Function by Echocardiography. J Am Soc Echocardiogr 2009, 22(2):107-133. 133.

15. Chahal NS, Lim TK, Chambers JC: Normative reference values for the tissue Doppler imaging parameters of left ventricular function: a population based study. Eur J Echocardiogr 2010, 11:51-56.

16. Nikitin NP, Witte KK, Thackray SD, et al: Longitudinal ventricular function: normal values of atrioventricular annular and myocardial velocities measured with quantitative two-dimensional color Doppler tissue imaging. J Am Soc Echocardiogr 2003, 16:906-921.
17. Madler CF, Pyne N, Derumeaux G, et al: Aging of left ventricular diastolic function affects the subendocardium and first involves the septum. EUR Heart J 2003, 24(Abstr supl):401

18. Onose $Y$, Oki T, Mishiro $Y$, et al: Influence of aging on systolic left ventricular wall motion velocities along the long and short axes in clinically normal patients determined by tissue pulsed Doppler imaging. J Am Soc Echocardiograph 1999, 12:921-926.

19. Palka $P$, Lange $A$, Fleming $A D$, et al: Age related transmural peak mean velocities and peak velocities gradients by Doppler myocardial imaging in normal subjects. Eur Heart J 1996, 17:940-950.

20. Sun JP, Popovic ZB, Greenberg NL, et al: Noninvasive quantification of regional myocardial function using Doppler derived velocity, displacement, stain rate, and stain in healthy volunteers: effect of aging. J Am Soc Echocardiogr 2004, 17:132-138

21. Mancia G, Backer G, Dominiczak A, Cifkova R, et al: The Task Force for the Management of Arterial Hypertension of the European Society of Hypertension (ESH) and of the European Society of Cardiology (ESC). Eur Heart J 2007, 28:1462-1536.

22. Yip G, Wang M, Zhang Y, Sanderson J: Left ventricular long axis function in diastolic heart failure is reduced in both diastole and systole: time for a redefinition? Heart 2002, 87(2):121-125.

23. Aurigemma G, Zile M, Gaasch W: Contractile behavior of the Left Ventricle in Diastolic Heart Failure - With Emphasis on Regional Systolic Function. Circulation 2006, 113:296-304

24. Galderisi M, Caso P, Dandrea A, et al: Pulsed tissue Doppler distinguishes physiologic by hypertensive determined left ventricular hypertrophy. Eur Heart J 2000, 21(abstr supl):485.

25. Nikitin N, Witte KK, Clark AL, et al: Color tissue Doppler-derived long-axis left ventricular function in heart failure with preserved global systolic function. Am J Cardiol 2002, 90:1174-1177.

26. Vinereanu D, Florescu N, Sculthorpe N, et al: Differentiation between pathologic and physiologic left ventricular hypertrophy by Tissue Doppler assessment of long axis function. Am J Cardio/ 2001, 88:53-58.

27. Emilsson $\mathrm{K}$, Wandt $\mathrm{B}$ : The relation between mitral annulus motion and left ventricular ejection fraction in atrial fibrillation. Clin Physiol 2000 20(1):44-49

28. Emilsson K, Wandt B: The relation between ejection fraction and mitral annulus motion before and after direct-current electrical cardioversion. Clin Physiol 2000, 20(3):218-224.

\section{doi:10.1186/1471-2261-13-92}

Cite this article as: Daskalov et al:: The relationship between mitral annular systolic velocity and ejection fraction in patients with preserved global systolic function of the left ventricle. BMC Cardiovascular Disorders 2013 13:92

\section{Submit your next manuscript to BioMed Central and take full advantage of:}

- Convenient online submission

- Thorough peer review

- No space constraints or color figure charges

- Immediate publication on acceptance

- Inclusion in PubMed, CAS, Scopus and Google Scholar

- Research which is freely available for redistribution 